\title{
Rapid colorimetric lactoferrin-based sandwich immunoassay on cotton swabs for the detection of foodborne pathogenic bacteria
}

\author{
Saleh Alamer ${ }^{\mathrm{a}, \mathrm{b}}$, Shimaa Eissa ${ }^{\mathrm{b}}$, Raja Chinnappan ${ }^{\mathrm{b}}$, Paul Herron ${ }^{\mathrm{a}}$, Mohammed Zourob ${ }^{\mathrm{b}, \mathrm{c}^{*}}$ \\ ${ }^{a}$ Strathclyde Institute of Pharmacy and Biomedical Sciences, University of Strathclyde, 161 \\ Cathedral Street, Glasgow, G4 0RE, United Kingdom. \\ ${ }^{\mathrm{b}}$ Department of Chemistry, Alfaisal University, Al Zahrawi Street, Al Maather, Al Takhassusi \\ Rd, Riyadh 11533, Saudi Arabia. \\ ${ }^{\mathrm{c}}$ King Faisal Specialist Hospital and Research Center, Zahrawi Street, Al Maather, Riyadh \\ 12713, Saudi Arabia.
}

*Corresponding author:

E-mail: mzourob@alfaisal.edu 


\begin{abstract}
Cotton swab is the conventional swabbing tool that is usually applied for collecting pathogens form contaminated surfaces, followed by cells lysis and genes extraction before subjecting to analysis. However, this way is time consuming and requires several steps and highly trained personnel. We present here a new cotton swab-based detection system integrating the bacteria collecting, preconcentration and detection on the Q-tips. The platform is based on a sandwich assay that can detect different pathogens visually by color change. Lactoferrin-immobilized cotton is used as a general capturing tool to collect various pathogens from surfaces. The presence of particular bacteria is then detected by immersing the cotton in antibodies attached to different coloured nanobeads. The target cell is captured between the lactoferrin and specific antibodyconjugated beads which results in certain color development. The effectiveness of this simply fabricated sensor was demonstrated using Salmonella typhimurium, Salmonella enteritidis, Staphylococcus aureus and Campylobacter jejuni. The intensity of the color on the cotton surfaces increased with increasing the concentration of the pathogenic bacteria. The detection limit was as low as $10 \mathrm{cfu} / \mathrm{ml}$ for Salmonella typhimurium and Campylobacter jejuni, $100 \mathrm{cfu} / \mathrm{ml}$ for Salmonella enteritidis and $100 \mathrm{cfu} / \mathrm{ml}$ for Staphylococcus aureus on chicken meat surface. Moreover, this method showed high selectivity and is further confirmed by loop-mediated isothermal amplification (LAMP) method. The simplicity and the low cost of this colorimetric sensor render it applicable to a wide range of other pathogens on different surfaces.
\end{abstract}




\section{Introduction}

Microorganisms such as bacteria, virus and fungi are found everywhere in the environment. These pathogenic microorganisms can cause human foodborne illness due to the ingestion of contaminated food or water [1]. In recent years, foodborne diseases are considered among the important public health problems in both developed and developing countries [2-5]. Outbreaks due to various foodborne pathogenic bacteria were recently reviewed in few reports $[1-2,4,6]$.

Salmonella can be transmitted to human through poultry products such as chicken meat and eggs [7-8]. Staphylococcus aureus $(\mathrm{Sa})$ is a potentially pathogenic bacteria responsible for food poisoning, frequently found in the contaminated foods such as raw or semi cooked meats, dairy products and ready-to-eat foods [9-10]. Campylobacter jejuni $(C j)$ plays a major role in bacterial diarrhoeal disease worldwide [11-12].

Due to the widespread of street foods, contaminated drinking water and preparation of ready-to-eat foods without proper safety, detection of foodborne pathogens is highly important to protect the consumers. Therefore, several conventional sensitive methods have been developed for the detection of foodborne pathogens. However, these methods are time consuming, require well experienced technicians and expensive. In order to protect the public health, the diseases spread has to be controlled, therefore, there is a demand for rapid and sensitive alternative methods. Several advanced methods have been developed based on various principles [1, 13-14]. Enzymelinked immunosorbent assay (ELISA) is one of the detection methods. However, ELISA suffers from the high-cost of the antibody production, pre-processing and long analysis time [15]. Polymerase chain reaction (PCR) is widely used for the detection of pathogens using specific primers. Real-time PCR (RT-PCR) is used for the quantitative detection of pathogens using DNA intercalating fluorescent dyes $[1,12]$. Multiplexed-PCR (mPCR) approach is used for the detection 
of more than one pathogen simultaneously $[12,15-16]$. Chen et al. have detected five pathogens simultaneously using the mPCR [17]. In addition to these methods, more sophisticated analytical methods such as liquid/gas chromatography coupled with mass spectrometry have been used for the analysis of pathogens. Despite that these methods are relatively sensitive and accurate, they cannot be used for point-of-care on-site pathogen detection and also very expensive.

Cotton swabs are widely applied for recovering pathogens form contaminated surfaces. This is usually followed by vortexing to release the pathogens in extraction buffer. After extraction the sample are then subjected to culturing or any other analysis technique. In this work, we aimed to exploit cotton swab for both sample collection and as a supporting matrix for the sensor. This would minimize the number of analysis steps and reduce the cost of the assay.

Lactoferrin (LF) is a globular glycoproteins. It binds to iron, DNA, RNA, polysaccharides, heparin, bacteria, proteins and viruses. Lactoferrin is mainly produced from saliva, milk and exocrine secretions [18]. High concentration of LF can be found in human colostrum. Number of studies referred to the ability of LF to bind most of the bacterial cells [19-21]. Some of these studies suggested that the binding between LF and bacteria is attributed to electrostatic interaction between LF molecule and bacterial cells [22]. Herein, taking advantage of the binding of LF to bacterial cells, we used LF as a general capturing agent for collecting various pathogens from the samples. Compared with antibodies, the use of LF in immunoassay can offer several advantages. Particularly, LF can be easily extracted in a low-cost compared with the long and expensive procedure of antibodies production.

A simple, versatile, portable, rapid and highly sensitive colorimetric immunoassay for bacteria detection is reported. The proposed sensor consists of a cotton swab-based sandwich LFimmunoassay. Lactoferrin-immobilized cotton swab is used to preconcentrate the bacteria cells 
from the chicken. Specific antibody coupled with colored nanopolymer beads were then used for the colour development. Different colours were used as indicator of the presence of various bacteria strains.

\section{Experimental section}

\subsection{Materials and Reagents}

Sodium periodate $\left(\mathrm{NalO}_{4}\right)$, phosphate buffer saline (PBS), Bovine serum albumin (BSA), 1-ethyl(3-dimethylaminopropy) carbodimide hydrochloride (EDC) and N-hydroxysuccinimide (NHS) were purchased from Sigma-Aldrich. Salmonella Typhimurium, St (ATCC14028), Salmonella Enteritidis, Se (ATCC13076), Staphylococcus aureus, Sa (ATCC6538), Listeria monocytogenes, Lm (ATCC7644), Escherichia coli, Ec (ATCC8739) and Campylobacter jejuni, Cj (ATCC 29428) were purchased from American Type Culture Collection (Manassas, VA). Stock cultures of all strains except $C j$ were stored at $-80^{\circ} \mathrm{C}$ in $20 \%$ glycerol solution. Prior to use, the frozen culture was activated in trypticase soy broth (TSB, Oxoid, Hampshire, UK) at $37^{\circ} \mathrm{C}$ with two consecutive transfers after $18 \pm 20 \mathrm{~h}$ incubation periods. The culture was centrifuged at $10000 \mathrm{Xg}$ for $10 \mathrm{~min}$ at $4^{\circ} \mathrm{C}$ and washed twice with trypticase soy broth. Cell suspensions were prepared and adjusted to an OD of 0.5 at $600 \mathrm{~nm}$ which is equivalent to $10^{8} \mathrm{cfu} / \mathrm{ml}$. Then the cells were serially diluted in trypticase soy broth. Stock cultures of $C j$ were grown for $4 \mathrm{~h}$ at $37^{\circ} \mathrm{C}$ and then for $24-48 \mathrm{~h}$ at $42^{\circ} \mathrm{C}$ under microaerophilic conditions in Bolton broth media (Oxoid LTD, UK) in an anaerobe jar with an active catalyst and a microaerophilic gas generator pack. 10-fold serial dilutions were made in maximum recovery diluent (Oxoid LTD, UK) and the viable cell numbers of $C j$ were determined by surface plating on Columbia blood agars (Oxoid LTD, UK). Anti- monoclonal antibodies of $S t$ 
and $S e$ and Murine anti- $C j$ and rabbit polyclonal antibody of $S a$ were purchased from Biospacific (Emeryville, CA, USA).

Lactoferrin from camel milk was purchased from Monojo (Amman, Jordan). Blue, orange and green dye coated polymer nano-beads with less than $50 \mathrm{~nm}$ containing carboxylic acid functional groups were purchased from Bangs Laboratories Inc. (Warrington, USA). Carboxylic acid functionalized cobalt based magnetic nano-particles with $50 \mathrm{~nm}$ diameter were purchased from Turbo beads (Zurich, Switzerland). LAMP detection kits for Salmonella typhimurium, Salmonella enteritidis and Campylobacter jejuni were obtained from Eiken Chemicals Co. Ltd (Tokyo, Japan).

\subsection{Procedures}

\subsubsection{Activation of cotton swabs}

$2.4 \mathrm{gm}$ of sodium periodate $\left(\mathrm{NaIO}_{4}\right)$ and $1 \mathrm{ml}$ of concentrated sulphuric acid $\left(\mathrm{H}_{2} \mathrm{SO}_{4}\right)$ in $100 \mathrm{ml}$ of water was mixed for $10 \mathrm{~min}$. The cotton swabs were then immersed in the solution overnight to oxidize the hydroxyl groups. The oxidized cotton was then washed extensively with cold distilled water. FTIR was used to confirm the conversion of the hydroxyl groups to aldehyde. The appearance of characteristic peak at $1730 \mathrm{~cm}^{-1}$ confirmed the formation of active aldehyde group on the cotton surface (Fig. S1 in supplementary information).

\subsubsection{Immobilization of Lactoferrin on Cotton}

The activated cotton was immersed in a solution of lactoferrin $(40 \mu 1,50 \mathrm{ng} / \mathrm{ml})$ and $2 \mathrm{ml}$ of PBS buffer overnight at $4^{\circ} \mathrm{C}$. After that, the lactoferrin-conjugated cotton swabs were washed extensively with PBS to remove the unbound lactoferrin. In order to block the unreacted active aldehyde groups, the cotton was incubated in $1 \mathrm{ml}$ of bovine serum albumin (BSA) for $30 \mathrm{~min}$. The 
cotton was then washed with PBS and stored in PBS at $4{ }^{\circ} \mathrm{C}$ until further use. The control samples were prepared by using the same protocol except that the $1 \mathrm{mg} / \mathrm{ml} \mathrm{BSA}$ was used instead of the lactoferrin.

\subsubsection{Immobilization of the antibodies on the nanobeads}

$1 \mathrm{ml}$ of $50 \%$ polymer nanobeads slurry (blue, orange and green) or a suspension of black magnetic nanobeads were washed with PBS buffer and collected by centrifugation at 16000-18000 rpm for $10 \mathrm{~min}$. The supernatants were removed and $1.5 \mathrm{ml}$ of buffer was added for each beads. The

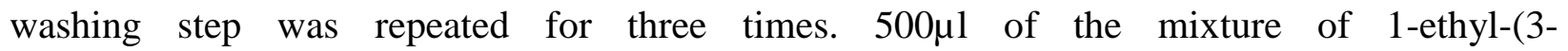
dimethylaminopropy) carbodiimide hydrochloride (EDC) and N-hydroxysuccinimide (NHS) solution were added to the $500 \mu \mathrm{l}$ of the beads and mixed for $20 \mathrm{~min}$ at room temperature. The activated beads were washed with PBS for three times and suspended in $0.5 \mathrm{ml}$ of PBS buffer. The beads were then incubated with $20 \mu \mathrm{l}$ of specific antibodies for different bacteria overnight. Each colored beads correspond to certain bacteria strain ( $S t, S e, S a$ and $C j$ ) specific antibodies were immobilized on black, blue, orange and green beads, respectively. After washing with PBS, $1 \mathrm{mg} / \mathrm{ml}$ of BSA was incubated with the antibodies-immobilized beads to block the unreacted active sites on the beads.

\subsubsection{Screening Procedure}

The screening procedure consists of two steps, the first step is the bacteria capturing step and the second step is the sandwich formation with the secondary antibody for the color development as shown in Scheme 1. In the first step, the cotton-immobilized lactoferrin was swabbed over the contaminated chicken surfaces to capture the bacteria. The chicken meat was initially contaminated with $S t, S e, S a$ and $C j$ bacteria cells and the number of the cells was determined by 
cell counting. After $10 \mathrm{~min}$, the cotton-immobilized lactoferrin-bacteria complex was washed with PBS buffer to remove the free cells from the cotton. In the second step (detection step), the bacteria were sandwiched between the lactoferrin and secondary detection antibody-conjugated nanobeads. The cotton swab lactoferrin-bacteria (cotton-LF-cell) complexes were immersed in a mixture of colored polymeric nanobeads and magnetic nanobeads linked with secondary antibodies in PBS buffer for 10 minutes. The cotton was then washed with PBS buffer to remove the unbounded beads. The color of the cotton swab indicates the specific bacterial stain present in the contaminated surfaces (Scheme 1).

\subsubsection{Quantitative detection}

The developed assay was intended to be used for visual observation of the colour change of the cotton swabs from white to colour via the naked eye. The intensity of the colour on the cotton swabs for the targeted bacteria was almost increased by increasing the bacteria concentrations from $10 \mathrm{cfu} / \mathrm{mL}$ to $10 \times 10^{8} \mathrm{cfu} / \mathrm{mL}$ for Salmonella typhimurium, Salmonella enteritidis, Staphylococcus aureus and Campylobacter jejuni. The images of the cotton swab were captured using smartphone. However, for quantitative measurements, the intensity of the colour was determined by using the Image J program developed at National Institute of Health after taking images for the cotton swabs using a smart phone. The calibration curves were plotted as the colour intensity for each bacteria concentration as a function of bacteria concentration.

\subsubsection{Loop Mediated Isothermal Amplification}

The lactoferrin-linked cotton swabs were used to collect the pathogens from artificially contaminated chicken surfaces with different concentrations of bacterial concentrations by swabbing. After 10 min, the DNA from the cells was extracted by dipping the contaminated cotton into extraction solution followed by incubation at $95^{\circ} \mathrm{C}$ for $5 \mathrm{~min}$. The extract was dissolved in 
Tris- $\mathrm{HCl}$ and centrifuge and the supernatant was used for the LAMP amplification. The master mix (consist of primer mix, dNTPs, buffer solution and template DNA was prepared according to the suppliers protocol. $20 \mu 1$ of master mix and $5 \mu 1$ of sample solution, positive control or negative control $+1 \mu 1$ of hydroxy naphthol blue (HNB ) dye are mixed in the reaction tubes and incubated at $60^{\circ} \mathrm{C}$ for $45 \mathrm{~min}$ in the heating block.

\section{Results and Discussion}

\subsection{Sandwich colorimetric lactoferrin immunoassay}

In this study, LF was used as a universal recognition receptor. Lactoferrin, was first conjugated to a cotton swab. The polyhydroxyl groups on the cellulose cotton were converted to active aldehyde groups using periodate oxidation. The formation of the aldehyde groups was further confirmed using FTIR by the appearance of characteristic peak at $1730 \mathrm{~cm}^{-1}$ [23] (Fig. S1 in supplementary information). The LF was then immobilized on the cotton by the reaction of the amino groups from the LF molecules with the aldehyde group on the cotton.

Here, we detected $S t, S e, S a$ and $C j$ as the most frequently reported pathogens responsible for foodborne illness. Taking advantage of the well established sandwich immunoassay format, this novel method utilizes the same principle using cotton swab as supporting matrix, LF as a capturing agent and various antibodies-conjugated colored nanobeads for detection as shown in scheme 1.

Swabbing the contaminated chicken surface with the LF immobilized cotton leads to capturing of the various pathogens. Then, the presence of particular bacteria strain is detected using specific antibody-conjugated colored nanobeads. Different antibodies were conjugated to different 
colored nanobeads. Therefore, the appearance of certain color on the surface of the cotton indicates the presence of a particular bacterial strain.

Figure 1 shows the detection results for the different bacteria strains ( $S t, S e, S a$ and $C j$ ) using the proposed colorimetric approach. The surface of the chicken was artificially contaminated with different concentration of bacteria cells. Then, the LF-cotton swabs were used to collect the different pathogen from the surface. After washing, the LF-bacteria complex was treated with different solutions of antibodies/colored beads. The unbound beads were then removed by washing with buffer or by passing the cotton swab over a magnetic sheet in the case of the magnetic particles. Figure 1A shows the gradual increase in the black colour on the LF/immunosensor with increasing the concentration of $S t$ on the chicken surface from 10 to $10^{8} \mathrm{cfu} / \mathrm{ml}$. When the sample contains higher cell count, more cells were captured by the LF molecules on the cotton. This in turn leads to the attachment of higher number of beads increasing the color intensity. As shown in Figure 1B, 1C, 1D similar trend was observed for the detection of Se using the blue beads, Sa using the orange beads and $C j$ using the green beads. The limit of detections (LOD) of this colorimetric assay visually were $10 \mathrm{cfu} / \mathrm{ml}$ for $S t$ and $C j, 100 \mathrm{cfu} / \mathrm{ml}$ for $S e$ and $100 \mathrm{cfu} / \mathrm{ml}$ for $S a$ on the chicken meat surface.

Figure 2 shows the calibration curves of our colorimetric assays for the different bacterial strains constructed by plotting the colour intensity determined using image $\mathrm{J}$ software versus the concentration. This method leads to accurate quantitative measurements and highly reproducible data with a relative standard deviations $<5 \%$ as shown from the error bars.

These LODs is comparable and in some cases better than the other reported assays for the targeted bacterial strains. For instance, the visual LOD of $S t(10 \mathrm{cfu} / \mathrm{ml})$ is significantly lower than other detection methods $[1,4,6,24]$. A fluorescence- based aptasensor has shown a LOD of $100 \mathrm{cfu} / \mathrm{ml}$ 
of $S t$ [25]. Recent approaches based on light scattering using immunomagnetic nanospheres and immunofluorescent nanospheres for the detection of $S t$ have achieved a LOD of $10 \mathrm{cfu} / \mathrm{ml}$ [26-27] which is comparable to the obtained LOD in this work. The reported LOD for $C j$ using the developed technique is also better that other reported electrochemical and mass-based immunosensors. Viswanathan et al [28] have developed an electrochemical immunosensors for the detection of multiple pathogens in the food using nanocrystal bio-conjugate and multiwalled carbon nanotube modified screen printed electrodes. The authors were able to detect as low as 400 $\mathrm{cfu} / \mathrm{ml}$ of $C j$ in milk samples using this approach. Nanoparticles enhanced Quartz crystal microbalance (QCM)-based immunosensor for $C j$ was also reported achieving a LOD of 150 $\mathrm{cfu} / \mathrm{ml}$ [29]. Song et al. [30] have achieved a LOD of $100 \mathrm{cfu} / \mathrm{ml}$ for $S e$ detection using a FRETbased biosensor which is comparable with our visual LOD. Another fluorescence-based aptasensor on graphene oxide for $S e$ has realised a LOD of $40 \mathrm{cfu} / \mathrm{ml}$ [31]. Using the quantitative measurements by the mobile camera, we can also detect around 40 cells. The other rapid detection methods for the detection of various food born pathogenic bacteria are summarized in the table 1 .

For $\mathrm{Sa}$, an aptamer-based biosensor employing single-walled carbon nanotubes (SWCNTs) as an ion-to-electron potentiometric transducer has been reported [32] with a LOD of $103 \mathrm{cfu} / \mathrm{ml}$. Multiple pathogen (including $S a$ ) detection method has been also reported using fluorescence sensor arrays [33]. Using the camera, the current approach can detect as low as 100 cells of $S a$ which is very good compared with other assays (Table-1). Highly sensitive methods with less than $10 \mathrm{cfu} / \mathrm{ml}$ have been reviewed recently $[1,6]$. However, our cotton based-method is simpler, easier to perform, portable, lower cost which makes it more suitable for point of care applications. It also offers numerous possibilities for versatile applications of different pathogens. It can be particularly 
useful in resource-constrained environments where sophisticated equipments is not always available.

\subsection{Selectivity experiments}

One of the main criteria of evaluating any sensor performance is the selectivity of the sensor for its specific target. In order to study the selectivity of our colorimetric LF-immunosensor, four LFcotton swabs were treated individually with $S t, S e, S a$ and $C j$ and each cotton swab was further incubated with different coloured antibody-conjugated beads. Only the cotton treated with the specific bacterial strain developed the corresponding color as shown in Figure 3. These results confirm the selectivity of our assay. No significant change in the cotton was observed when the sensor was immersed in the nonspecific beads indicating that the non specific adsorption on the sensors was very low.

\section{3.loop-mediated isothermal amplification}

LAMP method was used to validate the developed detection technique. The cotton swabs were used to collect certain bacteria cells from artificially contaminated surfaces. After the cells were recovered from the cotton in buffer, the DNA was extracted from the bacteria and subjected to LAMP assay. As shown in Fig. 4A, the color change from violet to sky blue indicates the presence

of the target gene of specific pathogenic bacteria. The amplification of DNA by LAMP was also confirmed by running $2 \%$ agarose gel electrophoresis as shown in Fig 4B. The same sample was then measured with our assay and the results were in good agreement with the LAMP assay. 


\section{Conclusions}

In this work, an equipment-free quantitative method for bacteria has been developed. The biosensor utilises cotton-swabs for collecting the bacteria and preconcentration, as well as supporting matrix for the sensing and lactoferrin as a capturing agent. Sandwich immunoassay was employed using various colored nanobeads. The new lactoferrin-immunosensor was used for the detection of Salmonella Typhimurium, Salmonella Enteritidis, Staphylococcus aureus and Campylobacter jejuni on chicken meat surface. The assays were further confirmed by the LAMP amplification assay. The results indicate that the developed method can be applied not only for qualitative determination, but also for semi quantitative detection. The method has achieved good sensitivity and selectivity for the targeted bacteria. Therefore, this simple, equipment-free, costefficient, portable and user-friendly method holds great potential for various point-of-care applications particularly in remote settings. 


\section{References}

[1] X. Zhao, C.W. Lin, J. Wang, D.H. Oh, Advances in rapid detection methods for foodborne pathogens, J. Microbiol. Biotechnol. 24(3) (2014) 297-312.

[2] E. Scallan, R.M. Hoekstra, F.J. Angulo, R.V. Tauxe, M.-A. Widdowson, S.L. Roy, J.L. Jones, P.M. Griffin, Foodborne Illness Acquired in the United StatesMajor Pathogens, Emerg. Infect. Diseases 17(1) (2011) 7-15.

[3] D. Ivnitski, I. Abdel-Hamid, P. Atanasov, E. Wilkins, Biosensors for detection of pathogenic bacteria, Biosens. Bioelectron. 14(7) (1999) 599-624.

[4] V. Velusamy, K. Arshak, O. Korostynska, K. Oliwa, C. Adley, An overview of foodborne pathogen detection: In the perspective of biosensors, Biotechnol. Adv. 28(2) (2010) 232-254.

[5] T.L. Switaj, K.J. Winter, S.R. Christensen, Diagnosis and Management of Foodborne Illness, Am. Fam. Physician 92(5) (2015) 358-65.

[6] A. Ahmed, J.V. Rushworth, N.A. Hirst, P.A. Millner, Biosensors for Whole-Cell Bacterial Detection, Clin. Microbiol. Rev. 27(3) (2014) 631-646.

[7] S.H. Park, M. Aydin, A. Khatiwara, M.C. Dolan, D.F. Gilmore, J.L. Bouldin, S. Ahn, S.C. Ricke, Current and emerging technologies for rapid detection and 
characterization of Salmonella in poultry and poultry products, Food Microbiol. 38 (2014) 250-62.

[8] M. Uyttendaele, P. De Troy, J. Debevere, Incidence of Salmonella, Campylobacter jejuni, Campylobacter coli, and Listeria monocytogenes in poultry carcasses and different types of poultry products for sale on the Belgian retail market, J. Food Prot. 62(7) (1999) 735-40.

[9] J. Kadariya, T.C. Smith, D. Thapaliya, Staphylococcus aureus and staphylococcal food-borne disease: an ongoing challenge in public health, BioMed. Res. int. 2014 (2014).

[10] J. Ei-Jakee, S.A. Marouf, N.S. Ata, E.H. Abdel-Rahman, S.I.A. El-Moez, A.A. Samy, W.E. El-Sayed, Rapid method for Detection of Staphylococcus aureus Enterotoxins in Food, Glob. Vet. 11(3) (2013) 335-341.

[11] A. Hadush, M. Pal, Detection of Campylobacter jejuni from food and its epidemiology, J. Public Health Epidemiol. 5(9) (2013) 357-361.

[12] J.W.-F. Law, N.-S. Ab Mutalib, K.-G. Chan, L.-H. Lee, Rapid methods for the detection of foodborne bacterial pathogens: principles, applications, advantages and limitations, Front. Microbiol. 5 (2014) 770. 
[13] P.K. Mandal, A.K. Biswas, K. Choi, U.K. Pal, Methods for rapid detection of foodborne pathogens: an overview, Am. J. Food Technol. 6(2) (2011) 87-102.

[14] P. Poltronieri, V. Mezzolla, E. Primiceri, G. Maruccio, Biosensors for the Detection of Food Pathogens, Foods 3(3) (2014).

[15] N. Lee, K.Y. Kwon, S.K. Oh, H.J. Chang, H.S. Chun, S.W. Choi, A multiplex PCR assay for simultaneous detection of Escherichia coli O157:H7, Bacillus cereus, Vibrio parahaemolyticus, Salmonella spp., Listeria monocytogenes, and Staphylococcus aureus in Korean ready-to-eat food, Foodborne Pathog. Dis. 11(7) (2014) 574-80.

[16] V. Van Giau, T.T. Nguyen, T.K.O. Nguyen, T.T.H. Le, T.D. Nguyen, A novel multiplex PCR method for the detection of virulence-associated genes of Escherichia coli O157:H7 in food, 3 Biotech. 6(1) (2015) 1-8.

[17] J. Chen, J. Tang, J. Liu, Z. Cai, X. Bai, Development and evaluation of a multiplex PCR for simultaneous detection of five foodborne pathogens, J. Appl. Microbiol. 112(4) (2012) 823-30.

[18] P.L. Masson, J.F. Heremans, C.H. Dive, An iron-binding protein common to many external secretions, Clin. Chim. Acta 14(6) (1966) 735-739. 
[19] A.S. Naidu, M. Andersson, A. Forsgren, Identification of a human lactoferrinbinding protein in Staphylococcus aureus, J. Med. Microbiol. 36(3) (1992) 177-183.

[20] A.S. Naidu, R.R. Arnold, Lactoferrin interaction with salmonellae potentiates antibiotic susceptibility in vitro, Diagn. Micr. Infec. Dis. 20(2) 69-75.

[21] T.J. Ochoa, T.G. Cleary, Effect of lactoferrin on enteric pathogens, Biochimie 91(1) (2009) 30-34.

[22] Y. Shi, W. Kong, K. Nakayama, Human lactoferrin binds and removes the hemoglobin receptor protein of the periodontopathogen Porphyromonas gingivalis, J. Biolog. Chem. 275(39) (2000) 30002-30008.

[23] X. Zhang, G. Shen, S. Sun, Y. Shen, C. Zhang, A. Xiao, Direct immobilization of antibodies on dialdehyde cellulose film for convenient construction of an electrochemical immunosensor, Sens. Actuators B: Chem. 200 (2014) 304-309.

[24] F.S. Ligler, K.E. Sapsford, J.P. Golden, L.C. Shriver-Lake, C.R. Taitt, M.A. Dyer, S. Barone, C.J. Myatt, The array biosensor: portable, automated systems, Anal. Sci. 23(1) (2007) 5-10.

[25] Y.F. Duan, Y. Ning, Y. Song, L. Deng, Fluorescent aptasensor for the determination of Salmonella typhimurium based on a graphene oxide platform, Microchim. Acta 181(5) (2014) 647-653. 
[26] C.-Y. Wen, J. Hu, Z.-L. Zhang, Z.-Q. Tian, G.-P. Ou, Y.-L. Liao, Y. Li, M. Xie, Z.-Y. Sun, D.-W. Pang, One-Step Sensitive Detection of Salmonella typhimurium by Coupling Magnetic Capture and Fluorescence Identification with Functional Nanospheres, Anal. Chem. 85(2) (2013) 1223-1230.

[27] C.F. Fronczek, D.J. You, J.Y. Yoon, Single-pipetting microfluidic assay device for rapid detection of Salmonella from poultry package, Biosens. Bioelectron. 40(1) (2013) 342-9.

[28] S. Viswanathan, C. Rani, J.A. Ho, Electrochemical immunosensor for multiplexed detection of food-borne pathogens using nanocrystal bioconjugates and MWCNT screen-printed electrode, Talanta 94 (2012) 315-9.

[29] N.A. Masdor, Z. Altintas, I.E. Tothill, Sensitive detection of Campylobacter jejuni using nanoparticles enhanced QCM sensor, Biosens. Bioelectron. 78 (2016) 328-36.

[30] Y. Song, W. Li, Y. Duan, Z. Li, L. Deng, Nicking enzyme-assisted biosensor for Salmonella enteritidis detection based on fluorescence resonance energy transfer, Biosens. Bioelectron. 55 (2014) 400-404. 
[31] W. Wu, Z. Fang, S. Zhao, X. Lu, L. Yu, T. Mei, L. Zeng, A simple aptamer biosensor for Salmonellae enteritidis based on fluorescence-switch signaling graphene oxide, RSC Adv. 4(42) (2014) 22009-22012.

[32] G.A. Zelada-Guillén, J.L. Sebastián-Avila, P. Blondeau, J. Riu, F.X. Rius, Label-free detection of Staphylococcus aureus in skin using real-time potentiometric biosensors based on carbon nanotubes and aptamers, Biosens. Bioelectron. 31(1) (2012) 226-232.

[33] R. Mungkarndee, G. Tumcharern, R. Thiramanus, I. Techakriengkrai, M. Sukwattanasinitt, Fluorescence sensor arrays for identification of foodborne pathogens, Anal. Meth. 7(18) (2015) 7431-7435.

[34] Zhang, J. Y., L. W. Dong, Q. Ren, X. Z. Wang, Y. Yang, W. Zhou, C. H. Zhu, X. Meng, and G. Q. Zhu (2014) Simple and rapid detection of Salmonella by direct PCR amplification of gene fimW. Curr Microbiol. 69: 429-435.

[35] Hyeon, J. Y., and X. Deng (2017) Rapid detection of Salmonella in raw chicken breast using real-time PCR combined with immunomagnetic separation and whole genome amplification. Food Microbiol. 63: 111-116.

[36] Ghosh Dastider, S., S. Barizuddin, N. S. Yuksek, M. Dweik, and M. F. Almasri (2015) Efficient and rapid detection of salmonella using microfluidic impedance based sensing. Journal of Sensors. 2015. 
[37] Waswa, J. W., C. Debroy, and J. Irudayaraj (2006) Rapid detection of Salmonella enteritidis and Escherichia coli using surface plasmon resonance biosensor. Journal of Food Process Engineering. 29: 373-385.

[38] Silva, N. F. D., J. M. C. S. Magalhaes, M. T. Oliva-Teles, and C. DelerueMatos (2015) A potentiometric magnetic immunoassay for rapid detection of Salmonella typhimurium. Analytical Methods. 7: 4008-4011.

[39] Huang, J., G. Yang, W. Meng, L. Wu, A. Zhu, and X. a. Jiao (2010) An electrochemical impedimetric immunosensor for label-free detection of Campylobacter jejuni in diarrhea patients' stool based on $\mathrm{O}$ carboxymethylchitosan surface modified Fe3O4 nanoparticles. Biosensors and Bioelectronics. 25: 1204-1211.

[40] Wang, X., Y. Du, Y. Li, D. Li, and R. Sun (2011) Fluorescent identification and detection of Staphylococcus aureus with carboxymethyl chitosan/CdS quantum dots bioconjugates. J Biomater Sci Polym Ed. 22: 1881-1893.

[41] Esteban-Fernández de Ávila, B., M. Pedrero, S. Campuzano, V. EscamillaGómez, and J. M. Pingarrón (2012) Sensitive and rapid amperometric magnetoimmunosensor for the determination of Staphylococcus aureus. Analytical and Bioanalytical Chemistry. 403: 917-925.

[42] Peedel, D., and T. Rinken (2014) Rapid biosensing of Staphylococcus aureus bacteria in milk. Analytical Methods. 6: 2642-2647. 


\section{Figure Captions}

Scheme 1: Schematic diagram of the lactoferrin-immunosensor for screening pathogenic bacteria.

Fig. 1. Screening results of different concentrations $\left(10\right.$ to $\left.10^{8} \mathrm{cfu} / \mathrm{ml}\right)$ of Salmonella typhimurium, Salmonella enteritidis, Staphylococcus aureus and campylobacter jejuni.

Fig.2 Calibration curves of the different bacteria using the colorimetric method; a plot of the colour intensity versus logarithm of the bacteria cell concentration.

Fig. 3. The cross-reactivity study of the colorimetric assay for the sample collected: A) $S t$, B) $S e$, C) $S a$ and D) $C j$ against $S t, S e, S a, C j$ and $E$. coli.

Fig.4 LAMP confirmation test for $C j$. The LAMP product visualized by colour change of the dye (B) as well as the bands observed in agarose gel electrophoresis (B). The change in the color of the HMB dye from purple to blue indicates the amplification of the specific gene. 
Table 1: Comparative analysis of repid detection methods of various foodborne pathogenic bacteria.

\begin{tabular}{|c|c|c|c|c|}
\hline Bacteria & Method & $\begin{array}{l}\text { Materials Used for } \\
\text { detection }\end{array}$ & $\begin{array}{l}\text { LOD } \\
\text { (cfu/ml) }\end{array}$ & Ref \\
\hline Salmonella enteritis & PCR & FimW gene amplification & 100 & [34] \\
\hline Salmonella & Rt-PCT & $\begin{array}{l}\text { Immunomagnetic } \\
\text { separation and whole } \\
\text { gene amplification }\end{array}$ & 10 & [35] \\
\hline Salmonella Enteritis & SPR & $\begin{array}{l}\text { Anti-salmonella antibody } \\
\text { coated SPR chip }\end{array}$ & 23 & [37] \\
\hline Salmonella enteritidis & FRET & $\begin{array}{l}\text { dsDNA -fluorophore- } \\
\text { quencher pair duplex } \\
\text { dissociation by the } \\
\text { nicking enzyme }\end{array}$ & 100 & [30] \\
\hline Salmonella enteritidis & Fluorescence & $\begin{array}{c}\text { Fluorescence switching } \\
\text { of fluorescent aptamer } \\
\text { adsorbed on the GO } \\
\text { surface }\end{array}$ & 40 & [31] \\
\hline Salmonella Typhimurium & Potentiometry & $\begin{array}{l}\text { magnetic sandwich } \\
\text { immunoassay }\end{array}$ & 4 & [38] \\
\hline Salmonella typhimurium & $\begin{array}{l}\text { Microfludic } \\
\text { Impedance }\end{array}$ & $\begin{array}{l}\text { Immuocomplex with } \\
\text { anti- } \\
\text { Salmonella antibodies }\end{array}$ & 1000 & [36] \\
\hline Campylobacter jejuni & & $\begin{array}{l}\text { O-carboxymethyl } \\
\text { chitosan surface } \\
\text { modified } \mathrm{Fe}_{3} \mathrm{O}_{4}\end{array}$ & 1000 & [39] \\
\hline Campylobacter jejuni & $\begin{array}{l}\text { Quartz crystal } \\
\text { microbalance( } \\
\text { QCM) }\end{array}$ & $\begin{array}{c}\text { Gold nanoparticle } \\
\text { conjugated Anti- } \\
\text { Campylobacter jejuni } \\
\text { antibody sandwich }\end{array}$ & 150 & [29] \\
\hline E. Coli & SPR & $\begin{array}{l}\text { Anti-e.Coli antibody } \\
\text { coated SPR chip }\end{array}$ & 25 & [37] \\
\hline
\end{tabular}




\begin{tabular}{|c|c|c|c|c|}
\hline Staphylococcus aureus & $\begin{array}{l}\text { Fluorescence } \\
\text { Microscopy }\end{array}$ & $\begin{array}{c}\text { Antibody conjugated } \\
\text { quantum dots }\end{array}$ & 900 & {$[40]$} \\
\hline Staphylococcus aureus & Amperometry & $\begin{array}{c}\text { gold screen-printed } \\
\text { electrodes and } \\
\text { immuno magnetic beads }\end{array}$ & 1 & [41] \\
\hline Staphylococcus aureus & Fluorescence & $\begin{array}{l}\text { Sephadex conjugated } \\
\text { human IgG Fc and } \\
\text { fluorescently labelled } \\
\text { S.A specific antibody- } \\
\text { andwich assay }\end{array}$ & 200 & {$[42]$} \\
\hline
\end{tabular}


Scheme 1:

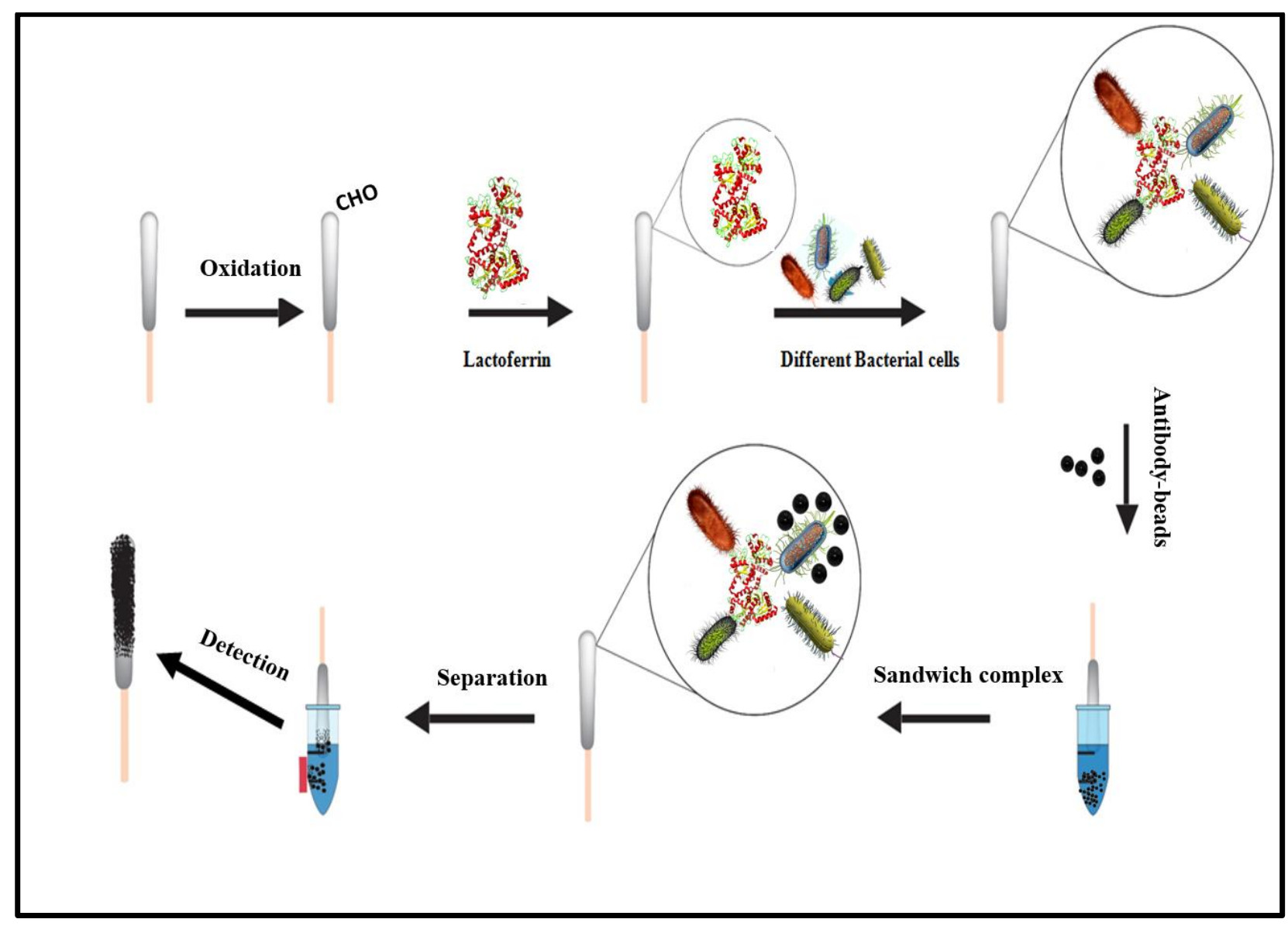


Fig.1:

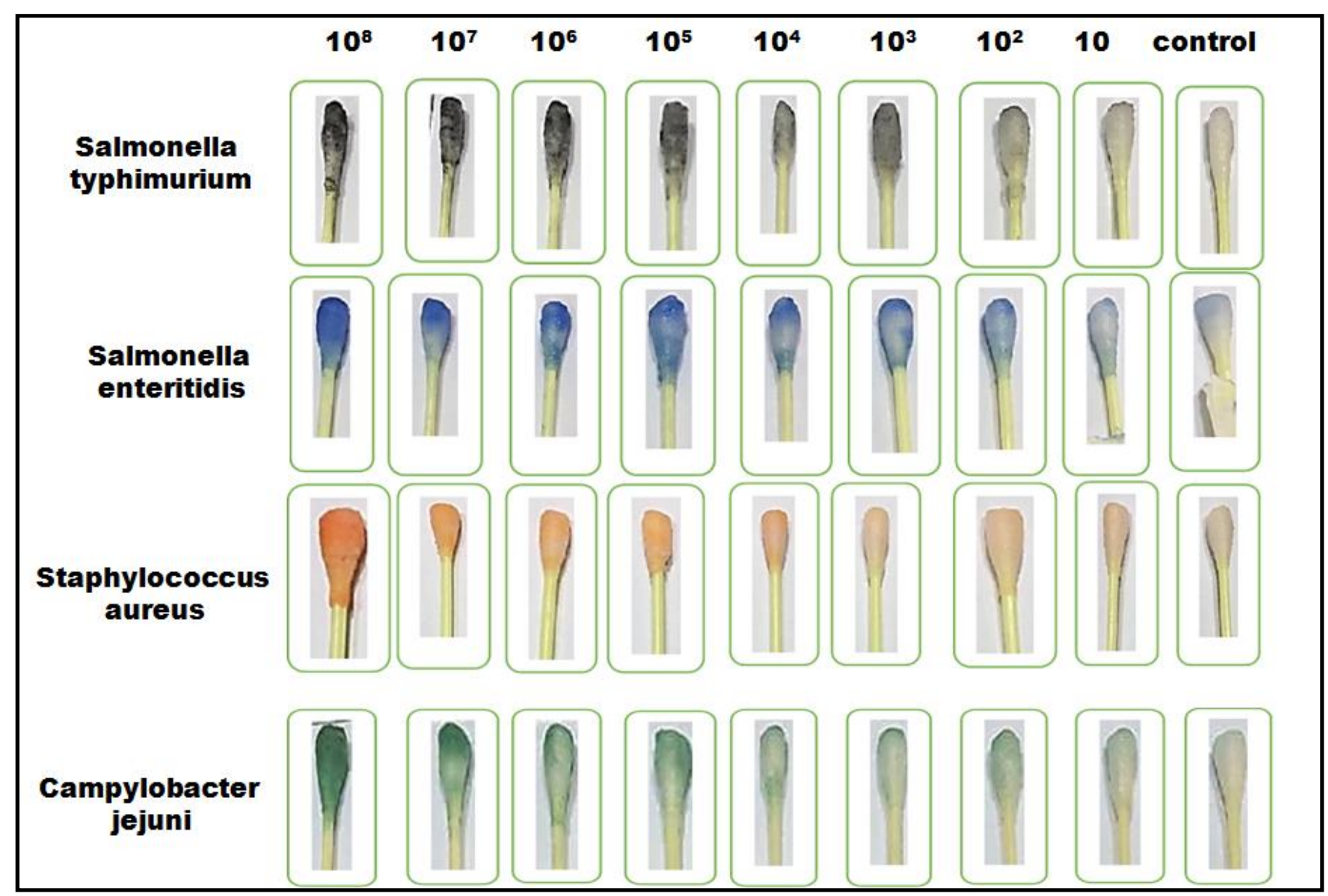


Fig. 2:

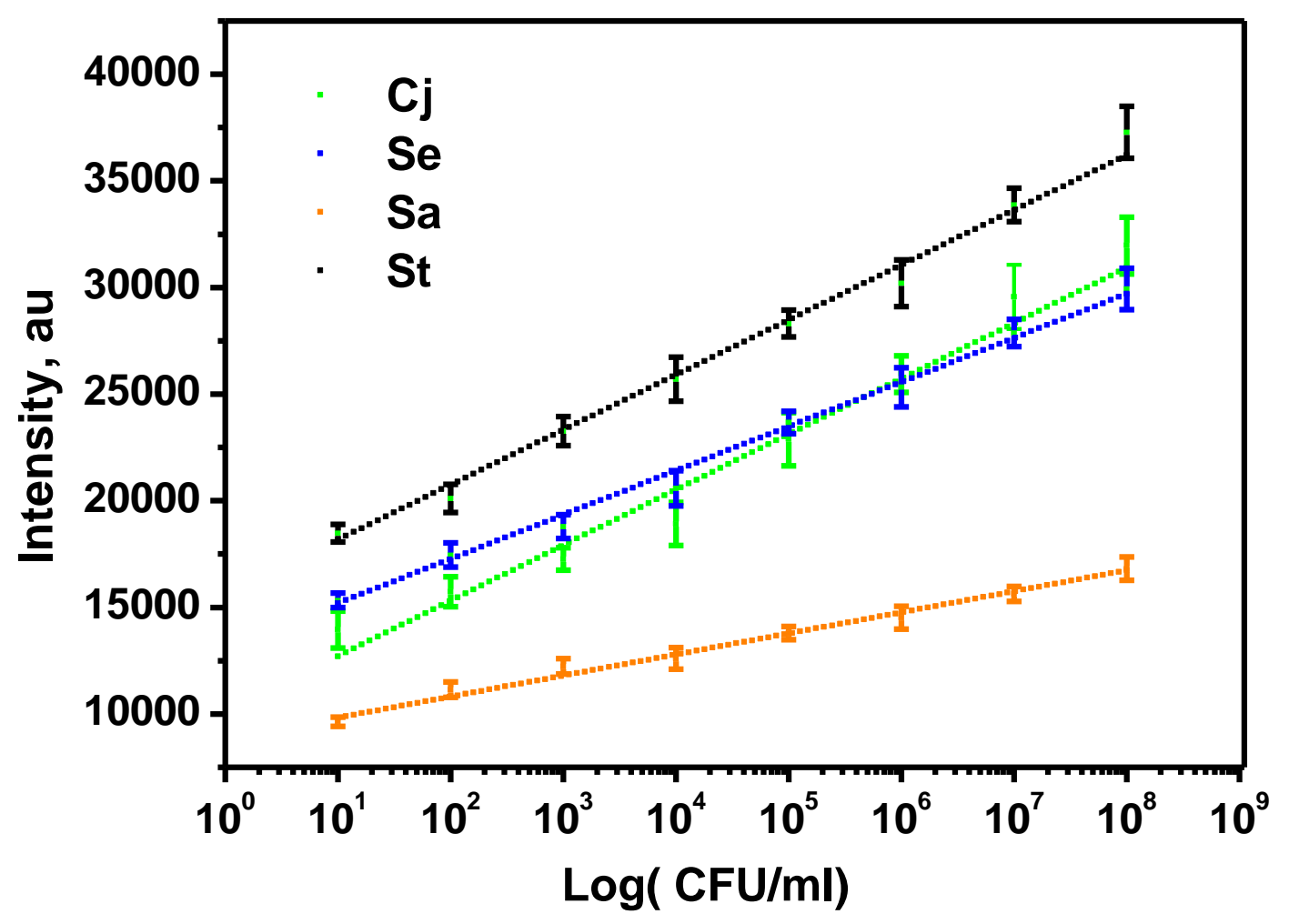


Fig. 3:

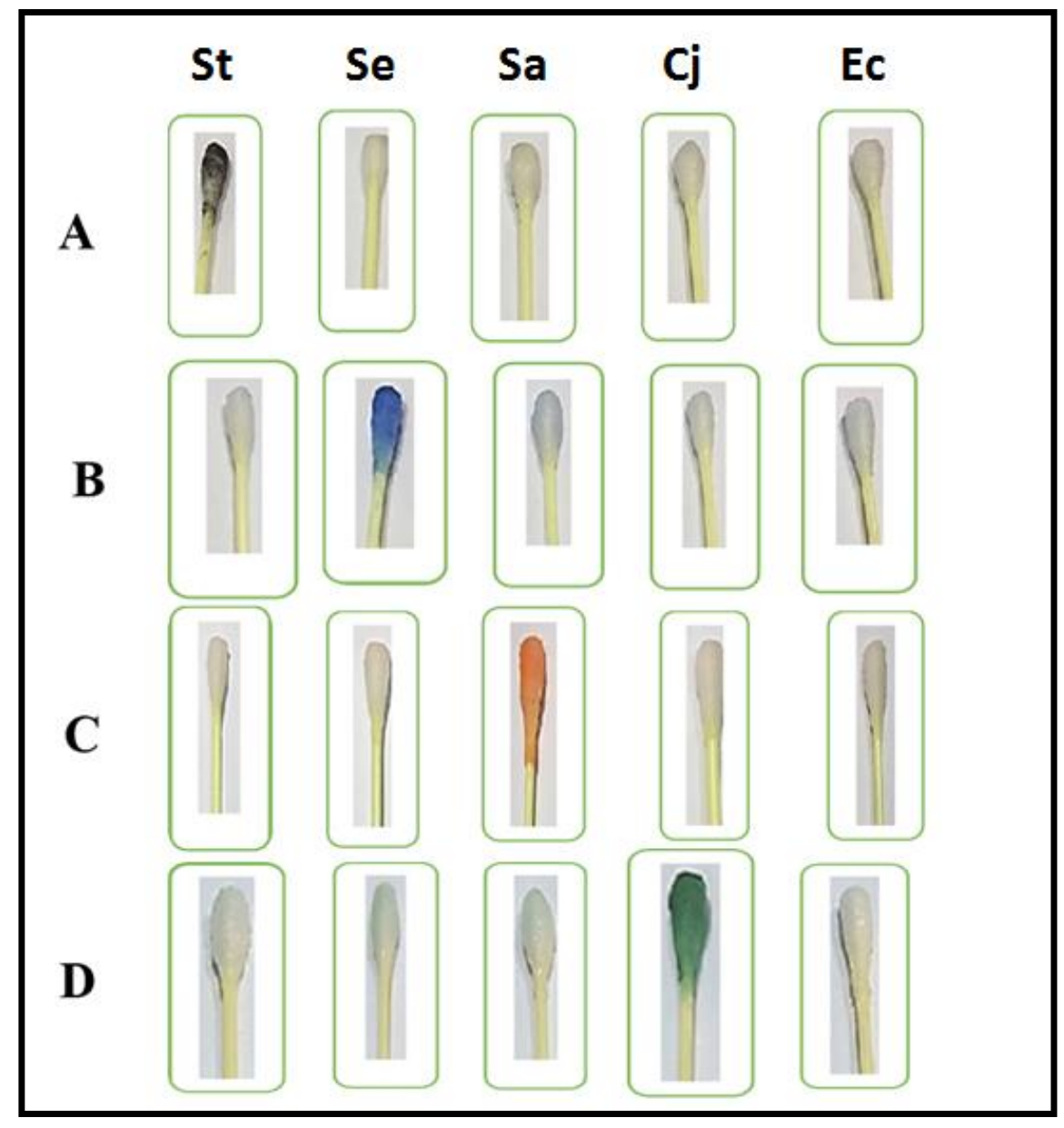


Fig.4

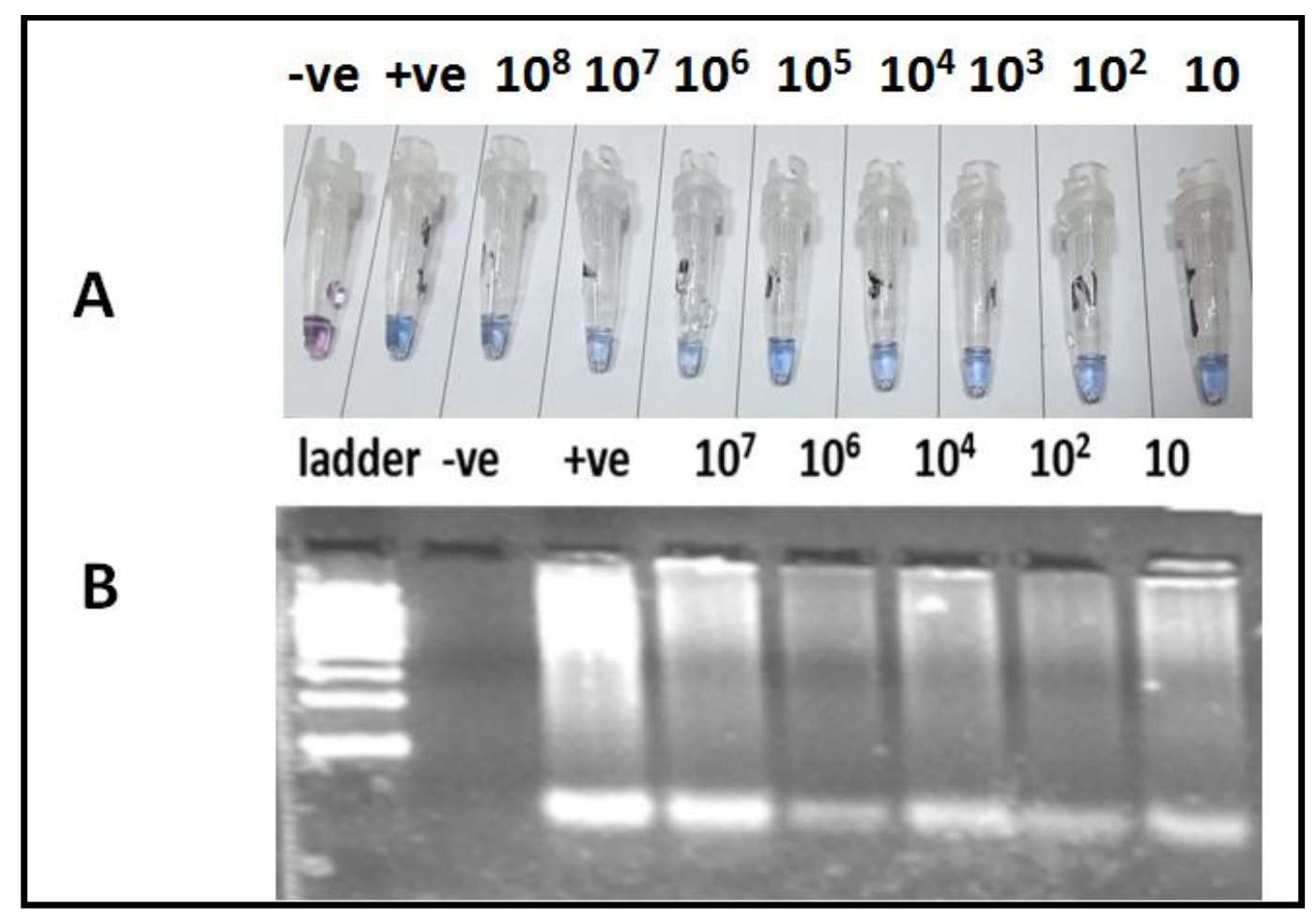

